\title{
Face Reorganization Method for Cyber Security System in Financial Sector Using FPGA Implementation
}

\author{
Mr. R.Vignesh Kumar ${ }^{1}$ Mrs.T.Kanimozhi ${ }^{2,}$ T. Uma Mahesweri ${ }^{3}$ \\ ${ }^{1}$ (M.E) Scholar-Embedded System, ${ }^{2}$ Assistant Professor, ${ }^{3}$ Assistant Professor \\ Department of Electrical and Electronics Engineering R.V.S.College of Engineering and Technology-Dindigul, \\ Tamilnadu- India
}

\begin{abstract}
Automated teller machines (ATMs) are well known devices typically used by individuals to carry out a variety of personal and business financial transactions and/or banking functions. ATMs have become very popular with the public for their availability and general user sociability. ATMs are now found in several locations having a regular or high volume of customer traffic. For instance, ATMs are typically found in restaurants, superstores, Convenience stores, shopping mall, schools, gas stations, hotels, work locations, banking centers, airports, entertaining establishments, transport facilities and a myriad of other locations. This has added new competences and features, though most of the time, the executions are registered and networking is not always possible. Yet there is an increasing demand for advanced banking, where appliances respond automatically to changing environmental conditions and can be easily controlled through one common device. This paper offerings a possible solution whereby the user controls devices by employing a central Field Programmable Gate Array (FPGA) controller to which the devices and sensors are interfaced. Control is transferred to the FPGA from a mobile phone through its GSM interface. ATMs are typically available to consumers on a continuous basis such that consumers have the ability to carry out their ATM financial transactions and/or banking functions at any time of the day and on any day of the week.
\end{abstract}

Keywords: FPGA, GSM, Face reorganization, SIM, ATM

\section{Introduction}

In this paper we can create the new generation ATM machine which can be operate without the ATM card. In this system ATM machine can be operator by using our SIM card and Face identification. When we insert our SIM in the reader unit of the ATM machine it transfers the mobile to the server. In server we can gather the related information of the mobile number (i.e.) the user's particulars of Bank account and their photographs etc. This paper presents a possible solution whereby the user controls devices by employing a central Field Programmable Gate Array (FPGA) controller to which the devices and sensors are interfaced. According to increasing development of technology and in order to approaching most citizen services are presented electronically

Using clever electronic cards. On the subject of this statistic, people have numerous smart cards which are increasing in number every day. In the face of so many advantages, these cards have various disadvantages such as multiplicity, difficult to carrying, inaccessibility of card readers in many places, waiting in the lines of ATMs, etc. In this paper we will present a new method named as multipurpose smart SIM card in order to resolve these problems. The Recommended SIM card, worked based on the mobile database architecture that we will discuss about this architecture and location dependent queries processing in it.Then we will study the difficulty of finding the nearby and best unoccupied ATM as a case study and at last we will propose a method to authenticate users in this system.

\section{Existing System:}

Existing ATMs are convenient and easy to use for most consumers. Existing ATMs typically provide directions on an ATM display screen that are read by a user to provide for collaborative operation of the ATM. Having read the display the commands, a user is able to use and operate the ATM via data and information pass on a keypad. However the drawback in the existing system is that the user must carry their ATM card without fail. But in many cases we fail to recall it. So only we designed this system which services us in the ATM machine without the ATM card. 
3.1BLOCK DIAGRAM:

\section{Proposed System:}

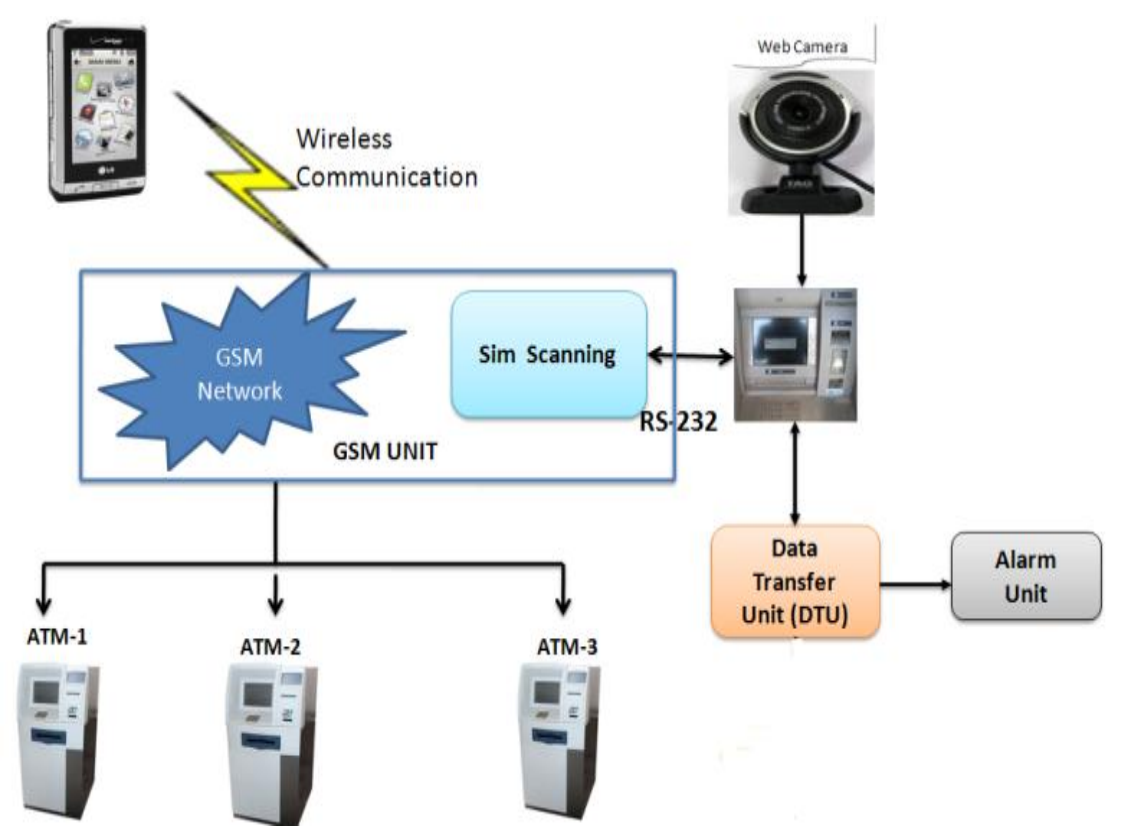

\subsection{Mobile Section}

Figure (3.1)Proposed Technique

\subsubsection{Status page}

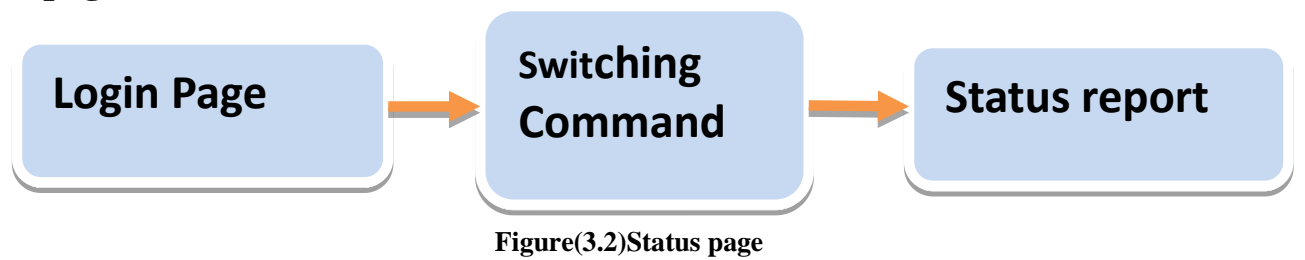

\subsection{WORK FLOW OF THE PROPOSED TECHNIQUE}

In this proposed system we have created the new generation ATM machine which can be operator without the ATM card. By using this scheme ATM mechanism can be operated using our SIM and Face identification. When we insert our SIM in the reader unit of the ATM machine it transfers the mobile to the server. In server we can gather the related information of the mobile number (i.e.) the user's particulars of Bank account and their photographs etc. The camera presented near the ATM machine will capture the user's image and compare it with the user image in the server using MATLAB.

Only when the image matches it requests the pin number and further operations will starts. Otherwise the process will terminate automatically. So by using this system necessity of ATM card is entirely eliminated. Here we can operate the ATM machine by using our SIM card itself. Using this system we can avoid malfunctions. Also our transaction will be greatly secured. Additionally more application can also be added in this system. Here we can implement multiple bank account details into one ATM and we can use one ATM card for withdrawing our different bank accounts. Also Another one application of this system is to find the nearest ATM centre which is working properly. With the help of our GSM technology. 


\section{User Authentication Methods}

\subsection{FACE REORGANIZATION PROCESS}

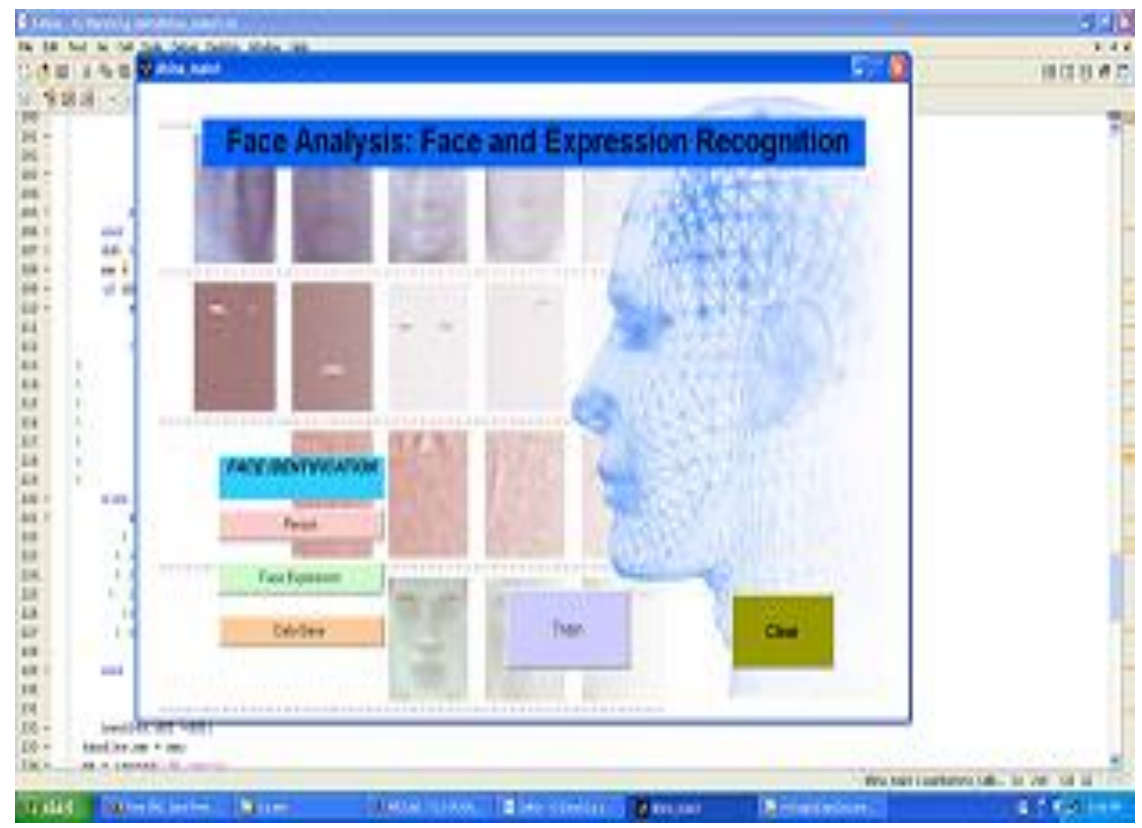

Figure (4.1) Step-1

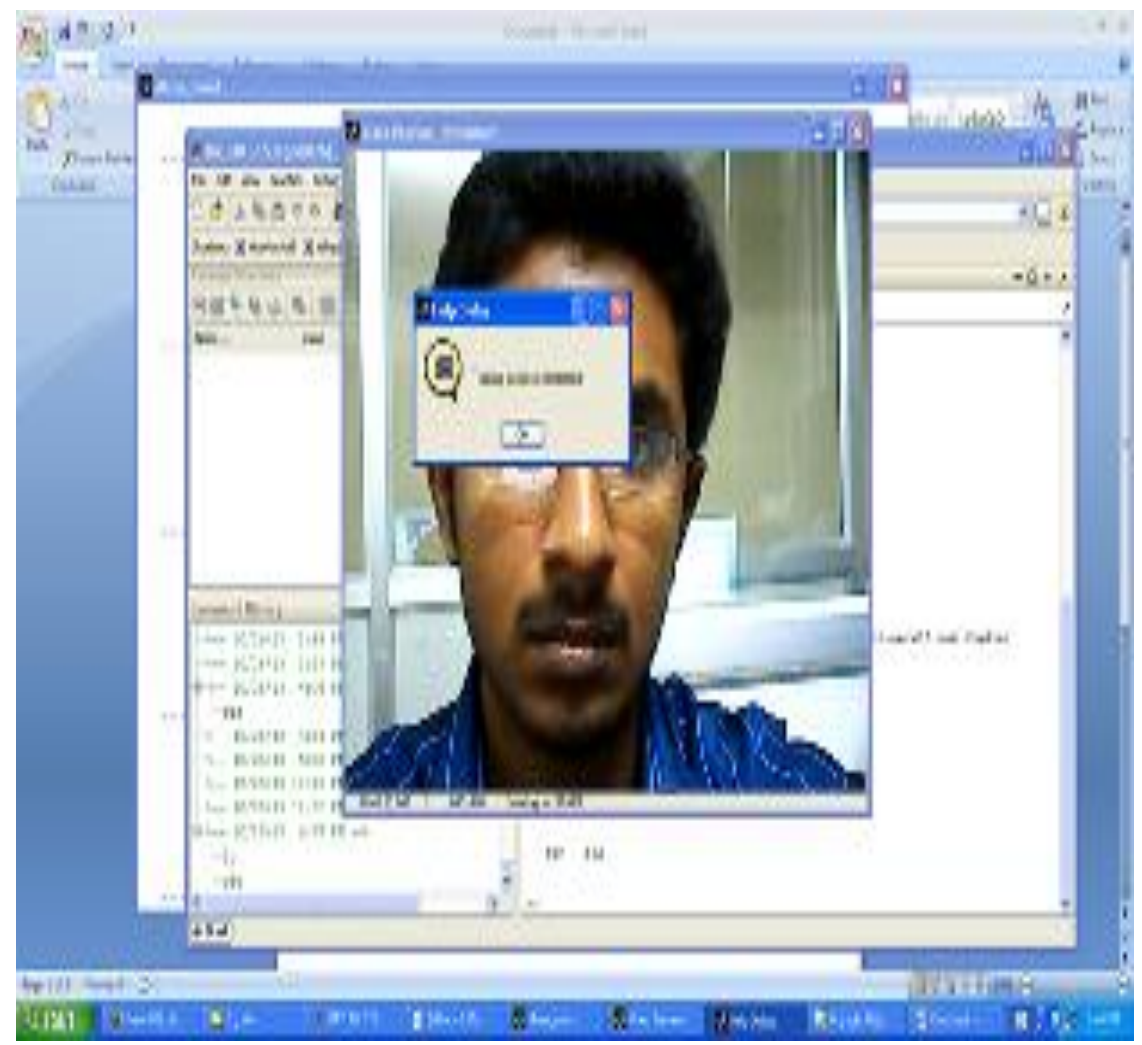

Figure (4.2) Step-2 


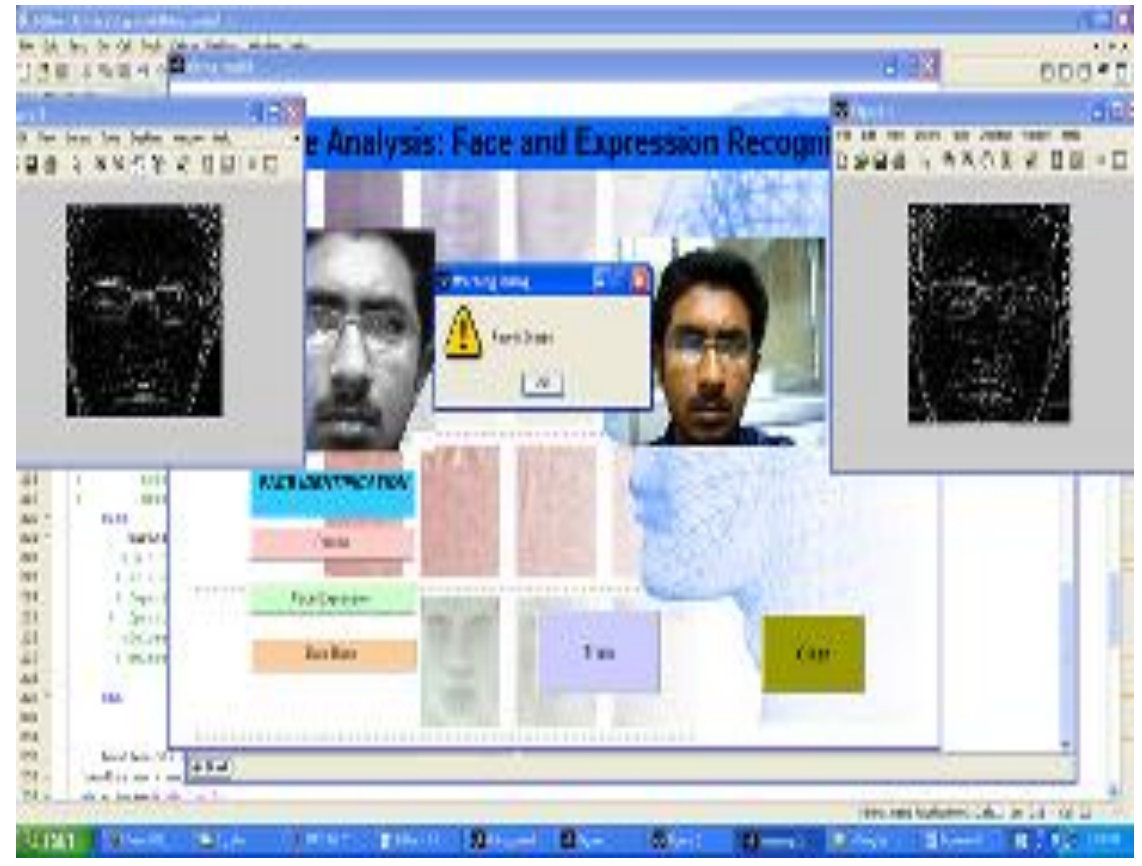

Figure (4.3) Step-3

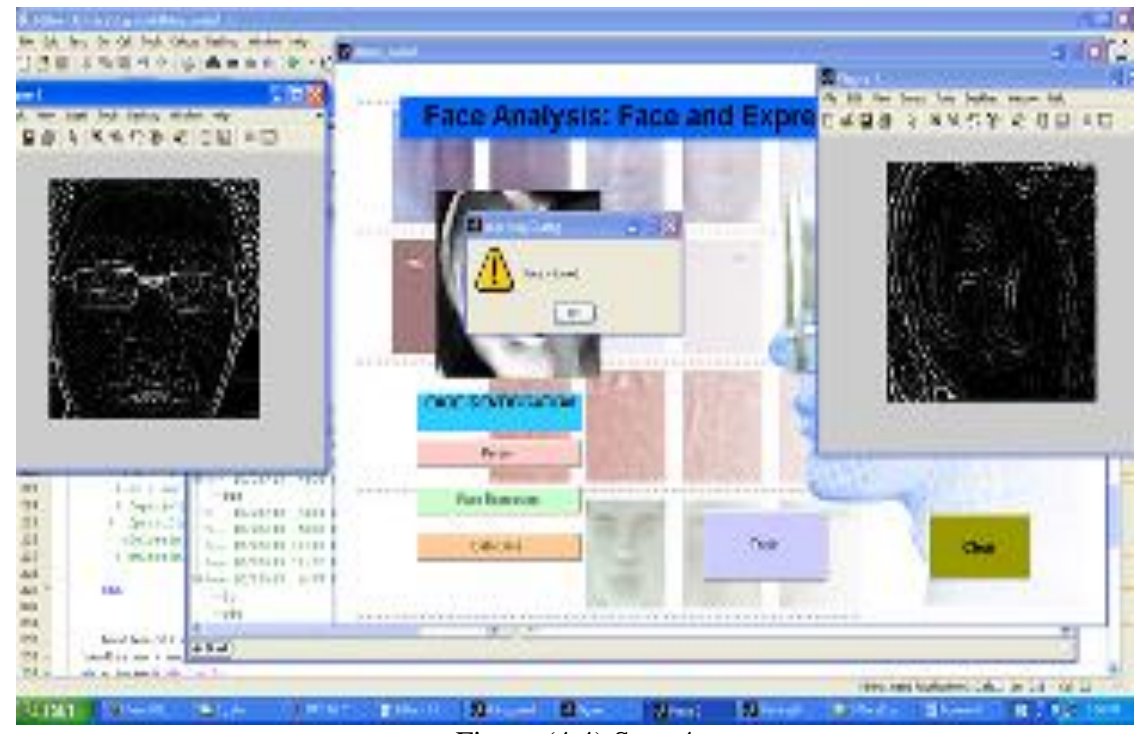

Figure (4.4) Step-4

\section{Conclusion}

The VHDL code was simulated and synthesized finally it was implemented in FPGA successfully. During the examination we find out that the face detection using Mat lab execution, There It proves to us that the detection algorithm can detect the face and the ATM was operated successfully using Visual studio. Also the embedded smart banking security system is executed

\section{AUTHORS PROFILE}

R.Vignesh Kumar was born in 1990 Tamilnadu , India..He received the B.E degree in electrical \& electronics engineering from RVS College of engineering \& tech, india in 2012. And presently doing his Master of Engineering in Embedded Systems in RVS College of engineering \& tech, india. His current research includes "Digital image processing \& FPGA implementation. 


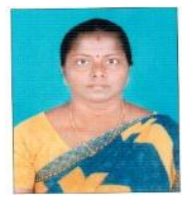

T. Kanimozhi was born in Tamilnadu, India in 1980, she received the B.E degree in electrical \& electronics engineering from the Madurai kamaraj university India in 2001 and the M.Sc. Degree in power engineering from Nanyang technological university, Singapore in 2009. She is currently working as an assistant professor in RVS College of engineering \& tech., India. Her current research interests included renewable energy sources, and power management.



T. Uma Mahesweri was born in Tamilnadu in 1980 , India, she received the B.E degree in electrical \& electronics engineering from the Madurai kamaraj university, India in 2004 and the M.E., degree in power electronics and drives from P.S.N.A college of engineering and Technology, Dindigul in 2009. She is currently working as an assistant professor in RVS College of engineering \& tech., India. Her current research interests included renewable energy sources, and Power Electronics.

\section{References}

[1] M. Ejiri, T. Uno, M. Mese and S. Ikeda, "A Process for Detecting Defects in Complicated Patterns," Computer Graphics and Image Processing, Vol.2, No.3-4, 1973, pp. 326-339.

[2] S. Kashioka, M. Ejiri and Y. Sakamoto, "A Transistor Wire-Bonding System Utilizing Multiple Local Pattern Matching Techniques,” IEEE Trans. on SMC, Vol.SMC-6, No.8, Oct. 1977, pp. 562-570.

[3] H. Yoda, Y. Ohuchi, Y. Taniguchi and M. Ejiri, "An Automatic Wafer Inspection System Using Pipelined Image Processing Techniques," IEEE Trans. on PAMI, Vol. PAMI-10, No.10, 1988, pp.4-16.

[4] M. Ejiri, H. Yoda, H.Sakou and Y. Sakamoto, "Knowledge-Directed Inspection for Complex Multilayered Patterns," Machine Vision and Applications, vol.2, no.3, 1989, pp.155-166.

[5] D. Barbara, "Mobile computing and databases - a survey", IEEE Transaction on Knowledge and Data Engineering, vol. 11, no.I, pp. 